\title{
KAJIAN DEMAM PANGGUNG SEBAGAI PENDUKUNG PERANCANGAN VISUAL FILM ANIMASI PENDEK TENTANG RASA TAKUT TAMPIL DI DEPAN UMUM
}

\author{
Ratu Tsamara Alyda1), Frans Santoso ${ }^{2)}$ \\ School of Design, Universitas Bina Nusantara \\ tsamaraalyda@gmail.com
}

\begin{abstract}
Abstrak
Tujuan riset ini adalah untuk mencari cara yang pas untuk menceritakan orang yang sedang demam panggung dalam bentuk short animation. Untuk mendapatkan eksekusi desain yang memiliki kedalaman konseptual, penulis akan memakai metode pengumpulan data dengan pendekatan kualitatif dengan cara wawancara narasumber yang cocok untuk bidang demam panggung dan juga desain, serta melakukan observasi akan animasi-animasi atau referensi lainnya yang dapat membantu penulis mandapatkan pemahaman mendalam. Hasil yang didapatkan akan digunakan sebagai acuan penulis untuk membuat short animation yang sesuai dan menarik.
\end{abstract}

Kata Kunci: Demam panggung, public speaking, visual

\begin{abstract}
The purpose of this research is to find the right way to tell people who are effected by stage fright. To get a design execution that has conceptual depth, the writer will use a method of data collection with a qualitative approach by interviewing sources that are suitable for the field of stage fright and also design, as well as observing animations or other references that can help the writer in understanding deep. The results obtained will be used as the author's reference to make appropriate and interesting short animation.
\end{abstract}

Keywords: Stage fright, public speaking, visual

Correspondence author: Ratu Tsamara Alyda, tsamaraalyda@gmail.com, Jakarta, Indonesia

This work is licensed under a CC-BY-NC

\section{PENDAHULUAN}

Demam panggung atau takut akan berbicara di depan publik adalah hal yang dialami oleh banyak orang dari berbagai latar belakang. Mulai dari anak sekolah yang harus presentasi, sampai penyanyi terkenal yang harus tampil di atas panggung. Seperti penyanyi Indonesia Rizky Febian, yang meski sudah tampil di berbagai kesempatan, vokalis Rizky Febian mengaku masih grogi jelang naik panggung. Tak jarang pelantun "Penantian Berharga" ini masuk ke toilet terlebih dahulu sebelum menampilkan aksi panggungnya. Menurut Forbes Magazine, sekitar $80 \%$ 
populasi orang merasakan kecemasan saat harus tampil di depan publik, $10 \%$ mengalami ketakutan extreme dan bisa dikatakan mempunyai fobia berbicara di depan umum atau "glossophobia", dan hanya 10\% sisanya yang tidak merasakan gugup atau bahkan suka dengan perasaan saat tampil di hadapan banyak orang. Ketakutan yang dialami itu berasal dari andrenalin dalam tubuh. Walau hal ini adalah hal yang wajar, ketakutan akan tampil di depan umum ini sudah memengaruhi banyak orang sceara negatif. Banyak kesempatan-kesempatan dalam karier, nilai, dan kehidupan secara general yang hilang karen seseorang takut akan maju dan berbicara di depan publik. Billionaire Warren Buffet menyatakan di HBO Documentary kalau dulunya takut sekali untuk berbicara di depan, tetapi dapat diatasinya dengan mengikuti kursus public speaking sampai bias karena kalau tidak bisa berbicara di publik maka kariernya tidak akan maju.

Visual adalah salah satu hal yang penting untuk manusia. Untuk lebih mengerti sesuatu, mengingat sesuatu, visual menjadi salah satu hal yang membuat manusia lebih paham akan suatu konteks. Untuk beberapa hal, visual lebih cepat ditangkap oleh orang dibanding dengan narasi. Karena itu sangat penting untuk menciptakan sesuatu dengan visual yang indah dan sesuai. Untuk menciptakan visual yang bagus, seorang harus memiliki pengertian tentang design dan juga tentang hal yang mau divisualisasikan

Animasi tiap tahun makin berkembang dan makin digemari oleh masyarakat. Mulai dari film-film layar lebar sampai dengan short animation yang di-upoload ke YouTube. Animasi juga sudah menjadi media yang cukup sering digunakan untuk menyampaikan pesan, secara educational maupun non-educational. Mulai dari memberikan pesan moral berat yang didapatkan di film-film layar lebar ataupun film singkat, sampai dengan sekadar menghibur penonton dengan cerita dan visual yang menarik dalam film animasi itu.

Maka dari itu, penulis membuat penelitian untuk menkaji visual rasa demam panggung, agar pembuatan animasi singkat dengan tema dan cerita yang sesuai akan lebih akurat. Dengan proposal ini, penulis akan menjabarkan rumusan masalah, teori, dan metode penelitian untuk riset visualisasi demam panggung ke depan.

\section{Tinjauan Pustaka}

Pengertian Animasi

Animasi berasal dari bahasa Inggris yaitu animate yang artinya menghidupkan, memberi jiwa dan mengerakkan benda mati. Animasi merupakan proses membuat objek yang asalnya objek mati, kemudian disusun dalam posisi yang berbeda seolah menjadi hidup. Di dalam animasi ada dua objek penting, yaitu objek atau gambar dan alur gerak. Pengertian Animasi Menurut Ibiz Fernandes dalam bukunya Macromedia Flash Animation \& Cartooning: A Creative Guide, animasi definisikan sebagai berikut: "Animation is the process of recording and playing back a sequence of stills to achieve the illusion of continues motion." Dilihat dari teknik pembuatannya, animasi terbagi menjadi 3 kategori, yaitu animasi stopmotion, animasi tradisional, dan animasi komputer.

Animasi Pendek dapat didefinisikan berdasarkan lama atau panjangnya cerita. Short Animation juga mempunyai format termasuk bermacam-macam jajaran atau barisan dari jenisjenis dan gaya visual dari cerita, sedangkan karakteristik animasi pendek biasanya berdurasi singkat (di bawah 24 menit), dan mempunyai 1 alur cerita (linear).

\section{Prinsip Dasar Animasi}

1. Solid Drawing. Menggambar sebagai dasar utama animasi memegang peranan yang signifikan dalam menentukan -baik proses maupun hasil- sebuah animasi, terutama animasi klasik. Seorang animator harus memiliki kepekaan terhadap anatomi, komposisi, berat, keseimbangan, pencahayaan, dan sebagainya yang dapat dilatih melalui serangkaian observasi dan pengamatan, dimana dalam observasi itu salah satu yang harus dilakukan adalah: menggambar.

2. Timing and Pacing. Timing adalah tentang menentukan waktu kapan sebuah gerakan harus dilakukan, sementara spacing adalah tentang menentukan percepatan dan perlambatan dari bermacam-macam jenis gerak. 
3. Anticipation. Anticipation adalah gerakan yang dilakukan sebagai ancang-ancang untuk mempersiapkan diri memasuki gerakan yang berikutnya. Contohnya: ancang-ancang yang dilakukan sebelum seseorang meloncat atau berlari.

4. Slow-in \& Slow-out. Slow in dan slow out merupakan gerakan perlambatan yang terjadi pada awal dan akhir suatu animasi. Gerakan perlambatan ini memberikan variasi pada suatu gerakan animasi ketimbang tidak ada perlambatan sama sekali.

5. Pose to Pose. pose to pose merupakan teknik menggambar frame awal dan akhir, kemudian dilanjutkan dengan mengisi frame-freame di antaranya.

6. Exagerration. Exaggeration adalah upaya untuk mendramatisir sebuah animasi dalam bentuk rekayasa gambar yang bersifat hiperbolis. Dibuat untuk menampilkan ekstrimitas ekspresi tertentu, dan lazimnya dibuat secara komedik. Banyak dijumpai di film-film animasi sejenis Tom \& Jerry, Donald Duck, Doraemon, dan sebagainya.

7. Appeal. Appeal dapat dibangun melalui pergerakan yang unik untuk masing-masing objek dan karakter sehingga kesemuanya memiliki personaliti yang khas. Hal ini akan membantu dalam menyajikan cerita yang ingin disampaikan melalui animasi itu sendiri.

\section{Cinematography}

Sinematografi sebagai ilmu terapan merupakan bidang ilmuy ang membahas tentang teknik menangkap gambar dan menggabung-gabungkan gambar tersebut sehingga menjadi rangkaian gambar yang dapat menyampaikan ide (dapat mengemban cerita).

The term cinematography is from the Greek roots meaning "writing with motion." At the heart of it, filmmaking is shooting - but cinematography is more than the mere act of photography. It is the process of taking ideas, words, actions, emotional subtext, tone, and all other forms of nonverbal communication and rendering them in visual terms.

Ada beberapa aspek dalam sinematografi yang harus diperhatikan, atau bisa dinamakan dengan "tools of cinematography" yaitu:

1. The frame

2. Light and color

3. The lens

4. Movement

5. Texture

6. Establishing

7. $P O V$

Dalam sinematografi juga ada berbagai macam tipe shot. Tiap tipe bagus untuk menggambarkan hal yang ber beda - beda. Dari buku Cinematography Techniques: The Different Types of Shots in Film oleh Timothy Heiderich dijelaskan sebagai berikut:

1. Extreme Long Shot: Untuk memperlihatkan perbedaan skala subjek dengan environmentnya. Contohnya, pendaki tebing terlihat seperti titik kecil dibanding dengan bukit salju yang besar karena shot diambil dari jauh. Shot ini cocok untuk memperlihatkan suatu setting. Long Shot: Jarak kamera dan subjek yang jauh mencerminkan juga jauhnya audience dengan emosi yang sedang ditampilkan. Shot ini membuat audience seperti bystander yang tidak begitu terlibat dalam situasi subjek.

2. Medium Long Shot: Di antara Long dan Short shot, digunakan lebih sebagai shot yang informatif dibanding emosional. Terlalu dekat untuk shot epic seperti long, tetapi terlalu jauh untuk tingkat emosi short shot, membuatnya menjadi shot yang natural.

3. Medium Shot: Inilah jarak shot yang cukup menggarap audience untuk merasakan emosi dan menjadi lebih personal dengan karakter yang ada dalam shot itu. Jarak seperti sedang berbicara dengan orang. 
4. Close Up: Lebih dekat secara jarak dan juga tingkat emosional dari medium shot, emosi dan tingkah karakter lebih terlihat. Shot ini akan kehilangan beberapa aspek informatif mulai dari setting, dan hal informatif lainnya, dan lebih fokus dan intim pada action karakter.

5. Extreme Close Up: Shot ini digunaka untuk menambah intensitas emosi secara dramatis, dengan jarak kamera dan wajah atau subjek apapun sangat dekat. Tidak harus mimik muka, tetapi peluru yang menembus kaca, lampu, atau apa pun itu jika didekatkan secara ekstrim akan menimbulkan perasaan yang lebih kuat.

6. Dutch Angle: Dengan memiringkan kamera sekian derajat, akan membuat efek ketidak seimbangan dan membuat audience merasa sedikit tidak nyaman.

Color Theory

Pada akhir tahun 1600, Sir Isaac Newton (1642 - 1727) melakukan sebuah eksperimen dengan prisms, cahaya, dan warna, yang akhirnya menjadi dasar pengertian kita akan warna. Teori warna dipakai sebagai acuan untuk setiap bidang ilmu. Teori warna pada dasarnya memiliki persamaan, antara teori Isaac Newton, Prang, Brewster, Oswald, dan Albert Munsel. Warna dapat memengaruhi kita secara emosional, psikologi, bahkan fisik, sering tanpa kita sadari. Warna dalam film dapat membangun harmoni atao tensi dalam scene, atau memberi perhatian untuk kunci tema yang sedang berjalan.

"When telling a story, colors can...

1. Elicit psychological reactions with the audience

2. Draw focus to significant details

3. Set the tone of the movie

4. Represent character traits and more

5. Show changes or arcs in the story"

6. How to Use Color in Film, Studio Binder

\section{Character Design}

Kata "desain karakter" biasa dipakai dalam konteks film, komik, dan game, di mana ada lebih dari satu karakter fiksi yang dapat dikenali oleh audience. Peran character designer adalah untuk membuat suatu gambar, untuk mem-visualkan suatu konsep yang bisa didiskusikan. Dari berbagai karakter yang ada dapat dikategorikan menjadi 2 jenis karakter yaitu karakter dalan wujud 2 dimensi dan wujud 3 dimensi. Adapun sebagai contoh wujud karakter 2 dimensi yaitu Wayang, Kartun, dan anime, contohnya seperti kartun Transformer dan anime One Piece. Untuk karakter dengan wujud 3 dimensi yaitu kartun Final Fantasy, Monster Inc, Finding Nemo, dan lain-lain.

\section{Animasi 3 Dimensi}

Visual

Menurut KBBI, Visual diartikan sebagai dapat dilihat dengan indra penglihat (mata); berdasarkan penglihatan: bentuk -- sebuah metode pengajaran bahasa; Menurut Budiman Hakim, Visual adalah syarat mutlak untuk memperkenalkan sebuah brand pada konsumen. Untuk menciptakan sebuah visual yang bagus, harus memiliki pengertian tentang desain. Menurut KBBI, desain/de·sain//désain/ adalah kerangka bentuk; rancangan: Desain adalah proses perancangan dengan keterampilan dan kreativitas melalui perasaan sehingga menghasilkan suatu karya. Menurut Kusrianto (2007), desain adalah berkaitan dengan perancangan estetika, cita rasa, serta kreativitas.

\section{Tinjauan Data}

\section{Demam Panggung}

Arti dari demam panggung menurut KBBI adalah kiasan perasaan tidak tenang (gugup) pada waktu berada di atas panggung (pentas). Panggung dalam konteks ini bisa berbeda-beda, tidak harus ada panggung secara literal, tapi penonton yang banyak juga termasuk. 
"The fear of public speaking or performance, often called stage fright, exacts a huge toll on self-confidence and self-esteem and causes some people to leave school or a job or pass up a promotion. Many, including seasoned professional performers, suffer in silent terror. And because they feel embarrassed, people try to keep their fear a secret, even from a spouse or other close family members or friends."

Demam panggung atau bisa dibilang kecemasan berbicara di depan public tergolong pada kriteria fobia sosial, maupun gangguan kecemasan sosial. Kondisi tersebut ditandai dengan ketakutan dalam menunjukan performasi maupun situasi interasionalnya dengan orang lain. Kondisi ini pun memengaruhi kualitas kehidupan individu, memengaruhi fungsi sosial dan relasi dengan komunitasnya. Menurut Monarth \& Kase (2007), faktor-faktor yang mempengaruhi individu mengalami kecemasan berbicara di depan public adalah sebagai berikut:

1. Faktor Biologis; Rasa takut dan cemas dialami oleh semua orang ketika berhadapan dengan bahaya, dan respon fisiologis yang muncul pertama adalah sistem saraf simpatis memproduksi \& melepaskan andrenalin yaitu hormone fight \& flight situasi bahaya. Kedua, detak jantung berdebar dengan kuat; tekanan darah naik; wajah bersemu merah. Ketiga, sensasi dingin dan gemetar pada tangan dan kaki. Keempat, nafas memburu dengan cepat; sulit mengatur pernafasan; dan mengalami sakit kepala ringan. Kelima, berkeringat pada sekujur tubuh.

2. Faktor Pikiran Negatif; Pikiran akan memicu respon biologis, sebaliknya adakalanya respon biologis yang menampakan kecemasan dan pikiran negatif akan menyertainya. Pikiran negatif yang umumnya timbul, pertama bahwa bicara di depan umum menakutkan. Kedua, pikiran yang terlalu berlebihan terhadap konsekuensi negatif dari suatu situasi sosial. Ketiga, penalaran emosi merupakan suatu pemikiran tentang adanya proses berkomunikasi.

3. Faktor Emosional; Saat kita menunjukan situasi takut, kita mengalami respon fisiologis, kognitif, dan perilaku yang menggambarkan situasi tersebut sehingga kita sendiri yang mengembangkan rasa takut terhadap situasi tertentu. Individu tersebut cenderung merasakan perasaan cemas, takut, kuatir, merasa tidak mudah menghadapi situasi sosial, tegang, panik, dan gugup menghadapi situasi berbicara di depan umum. Saat mereka menyadari implikasinya terhadap karir dan kehidupan sosial, dapat menyebabkan perasaan depresi, murung, frustasi, putus asa, dan perasaan takut.

Mengutip dari modul Pengantar Public Speaking karya Dr. Hendriyani, S.Sos., M.Si. dan Yohana Purnama Dharmawan, S.E. Pada waktu stres atau tertekan, tubuh merespons dengan memproduksi hormon adrenalin yang berlebihan. Semburan adrenalin menimbulkan reaksi yang berbeda pada diri setiap orang, dan tentunya hal ini dapat kita antisipasi dan atasi, antara lain:

1. Jantung berdegup lebih cepat dari biasanya.

2. Keluar keringat berlebih di bagian tubuh tertentu seperti telapak tangan, wajah, atau ketiak.

3. Tangan menjadi gemetar.

4. Lutut terasa lemas hingga terasa tidak sanggup menopang tubuh untuk berdiri.

5. Tenggorokan terasa tercekat sehingga suara menjadi parau, atau lebih buruk lagi: suara tidak bisa keluar.

6. Perut terasa sakit dan seperti ingin buang air besar.

7. Tidak bisa mengingat apa yang ingin disampaikan sekalipun sebelumnya sudah disiapkan.

"The Science of Stage Fright (and how to overcome it)" adalah animasi edukasional yang dibuat oleh Mikael Cho dan di produksi oleh KAWPA Studioworks. Animasi ini dirilis di YouTube oleh channel TED-ed, menjelaskan penjelasan secara scientific tentang rasa demam panggung. Animasi ini dibuat secara entertaining dengan visual yang cocok dengan topik yang sedang dibicarakan. Penulis dapat belajar tentang stage fright banyak dari video ini. 


\section{Social Anxiety}

Gangguan kecemasan sosial adalah salah satu gangguan mental yang paling umum. Ini biasanya dimulai pada awal hingga pertengahan belasan tahun, meskipun kadang-kadang bisa lebih awal pada masa kanak-kanak atau dewasa. Tanda tanda dan gejala emosi dan perilaku kecemasan sosial, Jiwo (2012) menjelaskan beberapa gangguan kecemasan sosial termasuk:

1. Takut secara berlebihan ketika berinteraksi dengan orang asing

2. Takut situasi di mana Anda dapat dinilai

3. Khawatirkan memalukan atau memalukan diri sendiri

4. Ketakutan bahwa orang lain akan melihat bahwa Anda terlihat cemas

5. Kecemasan yang mengganggu rutinitas harian Anda, pekerjaan, sekolah atau kegiatan lain

6. Menghindari melakukan sesuatu atau berbicara dengan orang karena takut malu

7. Menghindari situasi di mana Anda mungkin menjadi pusat perhatian

8. Kesulitan membuat kontak mata

9. Kesulitan berbicara

Sejumlah faktor dapat meningkatkan risiko terserang gangguan kecemasan sosial, (Tirto Jiwo, 2012) yaitu:

1. Perempuan. Perempuan lebih mungkin dibandingkan laki-laki untuk terkena gangguan kecemasan sosial.

2. Riwayat keluarga. Anda lebih mungkin untuk mengembangkan gangguan kecemasan sosial jika orang tua biologis atau saudara memiliki kondisi tersebut.

3. Lingkungan. Gangguan kecemasan sosial mungkin merupakan perilaku yang dipelajari. Artinya, Anda dapat terkenagangguan setelah menyaksikan perilaku cemas orang lain. Selain itu, mungkin ada hubungan antara gangguan kecemasan sosial dan orang tua yang sangat mengendalikan atauterlalu melindung anak-anak mereka.

4. Temperamen. Anak-anak yang pemalu, penakut, ditarik atau tertahan ketika menghadapi situasi yang baru atau orang-orang mungkin menghadapi risiko lebih besar.

5. Tuntutan pekerjaan atau sosial baru. Bertemu orang baru, memberikan pidato di depan umum atau melakukan presentasi pekerjaan penting untuk pertama kalinya dapat memicu gejala gangguan kecemasan sosial. Gejala ini biasanya memiliki akar pada masa remaja, namun.

6. Memiliki kondisi kesehatan yang menarik perhatian. Cacat wajah, gagap, penyakit Parkinson dan kondisi kesehatan lain dapat meningkatkan perasaanrendah diri, dan dapat memicu gangguan kecemasan sosial pada beberapa orang.

Holt, Heimberg, Hope, dan Liebowitz (1992) berteori bahwa ada 4 kategori situasi dimana gangguan kecemasan bisa terjadi. Situasi yang paling memicu gangguan kecemasan ini adalah situasi yang bersifat formal; seperti berbicara di depan audience banyak, tampil di panggung, memberi laporan kepada suatu grup, berbicara saat meeting dan hal - hal formal lainnya. Yang kedua adalah dimana situasi tidak formal, seperti berinteraksi oleh orang di suatu pesta, bertemu dengan orang baru, dan sebagainya. Ketiga, situasi dimana individu diharuskan untuk mengutarakan ketidak setujuan mereka, seperti sata harus mengembalikan barang yang sudah dibeli, atau menolak sales person saat ditawarkan barang. Terakhir, kecemasan ini juga bisa timbul saat sang individu di observasi oleh orang lain saat ia sedang melakukan aktivitas mereka. Individu ini akan takut akan persepsi orang itu akan dirinya.

\section{METODE PENELITIAN}

Metode riset yang akan saya gunakan untuk riset ini adalah dengan pendekatan Kualitatif. Pengumpulan data kualitatif dilakukan melalui pertanyaan - pertanyaan tidak terstruktur. Sudarwin (2002) menyatakan bahwa peneliti sebagai instrument dalam penelitian kualitatif mengandung arti bahwa peneliti melakukan kerja lapangan secara langsung dan bersama beraktivitas dengan orang-orang yang diteliti untuk mengumpulkan data Pada pendekatan ini, peneliti membuat suatu gambaran kompleks, meneliti kata-kata, laporan terinci dari pandangan responden, dan melakukan studi pada situasi yang alami. Dalam arti, alat yang digunakan untuk 
menanyai responden cenderung bersifat longgar, yaitu berupa topik, dan biasanya tanpa pilihan jawaban, sebab tujuannya untuk menggali ide responden secara mendalam. Metode ini lebih sering dipakai untuk meneliti hal - hal seperti fenomena sosial dan masalah manusia. Beberapa teknik pengumpulan data yang paling cocok digunakan untuk riset ini adalah wawancara, dan observasi.

\section{Wawancara}

Wawancara ada 2 tipe; terstuktur dan tidak terstruktur. Wawancara terstrukturdigunakan sebagai teknik pengumpulan data, bila peneliti atau pengumpul data telah mengetahui dengan pasti tentang informasi apa yang akan diperoleh. Sedangkan wawancara tidak terstruktur lebih bebas, peneliti hanya menanyakan garis besar dan bisa bercabang dari situ. Peneliti tidak mengikuti pedoman tertentu. Metode observasi dilakukan untuk mendapatkan data ruang (tempat), pelaku, kegiatan, objek, perbuatan, kejadian atau peristiwa, waktu, dan perasaan. Narasumber yang bisa saya wawancara untuk topik ini ada dari 2 bidang yaitu dari segi visual dan demam panggung. Untuk visual, saya mewawancarai alumni BINUS yang sukses dan sekarang berkerja di BASE Animation sebagai concept artist dan storyboard artist, Fierrany Halita. Narasumber kedua adalah narasumber untuk topik demam panggung, yaitu Salsabilla Firdausia, teman satu jurusan penulis yang juga seering mengalami demam panggung.

\section{Obeservasi}

Alasan peneliti melakukan observasi adalah untuk menyajikan gambaran realistik perilaku atau kejadian, untuk menjawab pertanyaan, untuk membantu mengerti perilaku manusia, dan untuk evaluasi yaitu melakukan pengukuran terhadap aspek tertentu melakukan umpan balik terhadap pengukuran tersebut. Menurut Spradley (1980) Tujuan observasi adalah memahami pola, norma dan makna dari perilaku yang diamati, serta peneliti belajar dari informan dan orang-orang yang diamati.

Untuk proyek ini, observasi yang penulis lakukan adalah observasi film - film pendek maupun Panjang yang berhubungan dengan tema Stage Fright ataupun untuk melihat referensireferensi. Seperti untuk segi cerita, film yang penulis observasi adalah Black Swan, Classroom, dan Dark Woods. Dan untuk segi visual banyak lagi film-film dan hal lainnya yang penulis observasi untuk referensi.

\section{HASIL DAN PEMBAHASAN \\ Hasil Wawancara}

Penulis sendiri adalah salah satu dari sekian banyak orang yang sering demam panggung akut saat harus berbicara di depan umum. Hal ini sudah penulis alami dari SD sampai sekarang di bangku perkuliahan. Setelah memasuki perkuliahan, ternyata mahasiswa jurusan animasi banyak yang tidak bisa berbicara di depan umum. Salah satu narasumber yang penulis ambil untuk topik demam panggung ini adalah Salsabila Firdausia, teman satu jurusan yang juga sering mengalami demam panggung saat harus berbicara di depan. Untuk mewawancarai Salsabila, penulis memakai pendekatan wawancara terbuka saja, karena kami adalah teman, wawancara ini lebih menjadi percakapan dan pembahasan tentang topik ini dan juga animasi yang penulis buat. Hal utama yang penulis tanyakan pada salbi adalah; apakah beatboard yang sudah dibuat; sudah cukup merepresentasikan perasaan demam panggung. Dari situ pembicaraan kami berkembang. Pertama Salbi mengusulkan bahwa lentera yang dibawa oleh Elda diganti menjadi hati saja, karena tidak masuk akal jika hatinya tiba - tiba keluar dari dadanya. Kemudian kunang - kunang harus di improve karena tidak begitu nyambung dan terkesan tiba - tiba. Ia juga menyarankan untuk mengubah tali yang menjerat lehernya karena terkesan tiba - tiba juga dan tidak masuk akal. Satu hal lainnya adalah dia menyarankan untuk membuat color scheme yang di hutan lebih cool tone dibanding warm, karena lebih terasa kengeriannya. Sehingga penulis membuat dari yang awalnya warm tone sampai ke scene classroom, dijadikan gradient.

Narasumber kedua adalah Fierrany Halita, alumni BINUS Animasi yang sekarang bekerja di BASE Animation, Bali. Ia adalah narasumber yang pas karena film animasi yang ia buat untuk 
Tugas Akhir menang beberapa awards. Wawancara ini tidak saya lakukan sendiri. Melainkan berkelompok dengan 3 teman saya lainnya yaitu Claudia Sabrina, Mathilda Eleonora dan Salbabila Firdausia. Inti dari wawancaras ini adalah untuk mengertahui bagaimana cara membuat Animasi yang bagus. Dari wawancara ini kami tahu bahwa Fierrany sendiri sudah suka dengan animasi dari SMP karena suka menonton Anime, tapi baru mendalami animasi lebih lanjut saat kuliah. Program yang ia pakai untuk pembuatan animasinya adalah Adobe Photoshop dan Adobe After Effect. Ia pribadi lebih menyukai animasi 2D karena looks nya yang bisa lebih di eksplor dan dimain - mainkan, tapi memang dari segi production, animasi 3D lebih efisien dan gampang untuk mengambil depth. Animasi yang sukses menurut dia adalah animasi yang cocok dengan target audience yang ingin dicapai. Tergantung dengan audience yang ingin di capai, animasi bisa berbentuk segala macam rupa. Jika memang animasi ini dibuat untuk anak - anak maka pembuat harus benar - benar paham apa yang membuat anak - anak tertarik, visual seperti apa, karakter seperti apa, story seperti apa, dan lainnya. Sama halnya dengan jika mau membuat animasi untuk dewasa, pembuat harus tau apa yang membuat orang dewasa tertarik. Jika membuat film animasi yang diperuntukan untuk dewasa tetapi dengan visual anak - anak, kemungkinan untuk sukses menjadi lebih kecil. Membuat film animasi tidak lah gampang, apalagi jika kita ingin membuat audience bersimpatik terhadap filmnya. Menurut fierrany, kunci untuk mendapatkan simpati audience adalah timing dan music. Jika timing di film pas, dan diiringi oleh musik yang pas, emosi akan lebih cepat ditangkap oleh audience. Pembahasan terakhir adalah bagaimana cara membuat story dan karakter yang menarik. Untuk story, memang membutuhkan proses yang lama karena biasanya ide akan muncul tiba - tiba atau dengan mencari inspirasi inspirasi dari luar. Setiap orang berbeda, bisa saja membuat cerita dari pengalaman pribadi, atau hal lainnya. Sedangkan untuk karakter, yang penting adalah loveable, dan sesuai dengan target audience.

\section{Hasil Observasi}

Dari segi desain, observasi yang penulis lakukan adalah dari mempelajari existing studies berupa film - film animasi maupun live action, sedangkan untuk observasi rasa demam panggung, penulis mempelajarinya dari beberapa cuplikan film-film, dan juga video YouTube. Dikarenakan tidak ada film yang memang bertemakan demam panggung, maka penulis tidak mempelajari hanya 1 film saja, tetatapi beberapa film yang menampilkan cuplikan berhubungan dengan demam panggung. Film pertama yang penulis observasi adalah "The King's Speech". "The King's Speech" adalah film biografi drama sejarah Britania Raya tahun 2010 yang disutradarai oleh Tom Hooper. Walapun film ini lebih menggambarkan orang yang gagap dibanding demam panggung, tapi banyak scene dimana penulis dapat meng-observasi gerak - gerik orang yang sedang gugup berbicara di depan, dan juga reaksi audience. Hal ini sama dengan Princess Diaries, dimana penulis men-observasi scene saat Mia debat di panggung dan gugup. Kemudian untuk lebih jelasnya, penulis banyak menonton video youtube dimana orang - orang gugup sampai terkena serangan panik saat harus berbicara di depan. Salah satu video yang cukup infortmatif adalah video dari BuzzFeed yang berjudul "When You're Afraid of Public Speaking". Video ini menggambarkan Sarah, protagonist yang kita ikuti berkhayal kalau teman-temannya mengejeknya saat ia di depan, dan ternyata mereka mendukungnya. Dari observasi di atas, penulis dapat menkaji data untuk film animasi pendek yang akan dibuat menjadi lebih akurat.

\section{Penulisan Judul}

Untuk pembuatan judul penulis ingin memberi judul 1 kata yang menggambarkan animasi ini tapi tidak secara terang - terangan. Ada 2 judul yang menjadi pertimbangan; yang pertama yaitu "Aphonia" dan yang kedua adalah "Butterflies". Kedua kata tersebut berarti Stage Fright, tetapi "Aphonia" lebih dekat dalam arti penyakit di mana seseorang tidak bisa mengeluarkan suaranya. Maka dari itu penulis memutuskan untuk memakai "Butterflies", suatu term yang biasa dipakai untuk menggambarkan perasaan gugup, seperti "Butterflies in my stomach". 


\section{Ringkasan Cerita}

Seorang gadis bernama Elda berjalan di tengah hutan mengikuti jalan setapak. Ia terus jalan kedepan, menelusuri jalan setapak yang tidak berujung. Ia pun mulai mengalami hal - hal aneh. Pohon yang berubah - ubah bentuk, perut sakit, dan hal aneh lainnya terjadi. Ditengah jalan ia sudah mau menyerah, muncul kunang - kunang yang kemudian memandunya. Setelah ia sampai ke tujuan, hutan yang tadinya disekelilingnya berubah menjadi ruang kelas. Makhluk - makhluk aneh yang tadinya mengerikan berubah menjadi teman - teman sekelasnya, dan kunang - kunang yang tadinya menuntunnya berubah menjadi teman baiknya. Perjalanan ditengah hutan yang tadi dia alami adalah visualisasi dari ketakutan anak ini untuk berbicara di depan kelas. Sekarang Elda berdiri di depan kelas, dengan kertas di tangannya, akan memulai presentasi.

\section{Target Audience}

Target audience untuk film ini adalag orang dari usia 15-20, karena di usia ini, SMA - kuliah, dan harus belajar untuk berbicara di depan. Dan usia ini mereka masih belajar akan diri mereka sendiri dan bagaimana cara berinteraksi dengan orang lain.

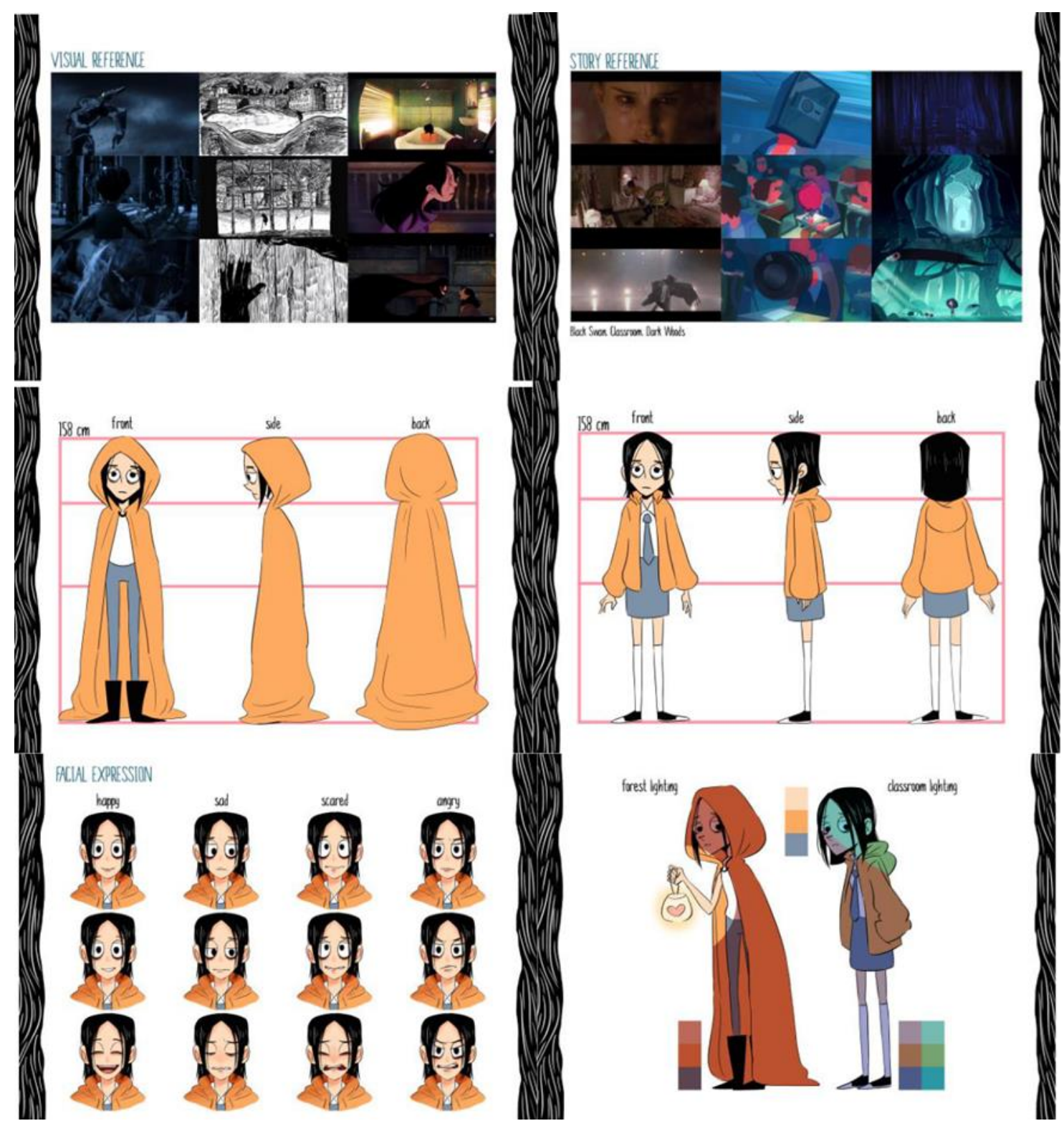

Gambar 1 Hasil Perancangan 


\section{SIMPULAN}

Dari riset yang sudah penulis lakukan, dapat ditarik kesimpulan seperti berikut. Rasa demam panggung untuk setiap orang berbeda, semakin gugup orang itu semakin parah juga gejalanya. Tapi secara general, demam panggung dapat dirasakan dengan jantung yang berdebar - debar, perut sakit, suara tidak bisa keluar, pikiran blank, kaki sudah digerakan dan tidak mau maju, dan keringat berlebihan. Tingkah orang yang sedang demam panggung juga bervariasi. Ada orang yang saking gugupnya ia jadi berbicara terlalu cepat dan tidak jelas, ada juga yang terdiam sangking ketakutannya. Untuk membuat animasi yang lebih menarik dan berkesan untuk orang, penulis membuat animasi ini menjadi lebih fantasi dengan cara memvisualisasikan gejala - gejala demam panggung dengan simbolisme - simbolisme. Ide cerita untuk membuatnya menjadi film dengan simbolisme diambil dari 3 film referensi yaitu Black Swan, Afternoon Class, dan Dark Dark Woods.

\section{DAFTAR PUSTAKA}

Bakhtiar, M. I., Saman, A., \& Aryani, F. (2017). Mengatasi Kecemasan Sosial Melalui Pendekatan Behavioral Rehearsal.

Brown, B. (2016). Cinematography: theory and practice: image making for cinematographers and directors. Focal Press.

Crossley, K. (2014). Character Design from the Ground Up: Make Your Sketches Come to Life. Hachette UK.

Fitrah, M. (2010). Rumusan Pemasaran melalui Desain Visual. 2018. Gavin Ambrose, Paul Harris. Design Th!nking. An AVA book.

Haryanti, L. P. S., \& Nia, T. (2012). Efektivitas metode terapi ego state dalam mengatasi kecemasan berbicara di depan publik pada mahasiswa fakultas psikologi uin syarif hidayatullah jakarta. Jurnal Psikologi UIN Syarif Hidayatullah Jakarta, 14(1), 32-40.

Istijanto, M. M., \& Com, M. (2005). Riset Sumber Daya Manusia Cara Praktis Mendeteksi Dimensi-Dimensi Kerja Karyawan. Gramedia Pustaka Utama, Jakarta.

Mollica, P. (2013). Color Theory: An essential guide to color-from basic principles to practical applications (Vol. 53). Walter Foster.

Nurhadiat, D. (2016). Pendidikan Seni Rupa untuk SMP kelas 2, 2004 Studio Binder, How to Use Color in Film,

Plattner, H. (2013). An introduction to design thinking. Iinstitute of Design at Stanford, 1-15. 